\title{
Gerenciamento estratégico de informação nas empresas industriais do setor de telecomunicações no Brasil
}

\section{Cecília Carmen Cunha Pontes}

\section{Resumo}

Realizou-se um estudo comparativo entre três indústrias do setor de telecomunicações sediadas no Brasil, focalizando a atenção para a capacitação da organização em gerenciar sistemas de informação para subsidiar o processo de desenvolvimento/ adaptação de novas tecnologias, sendo abordados os seguintes aspectos: caracterização da estratégia de negócios, política de treinamento de recursos humanos em P\&D e uso de redes corporativas de informação para o desenvolvimento de novas tecnologias.

\section{Palavras-chave}

Informação para negócios; Redes de informação corporativas; Transferência de informação em P\&D.

\section{INTRODUÇÃO}

Os avanços da ciência, intensificados nos últimos 30 anos, provocaram dramático crescimento de produtos baseados em novas tecnologias de informação relacionadas com a computação, telecomunicação, automação e robótica. Essas tecnologias estão induzindo, no mundo inteiro, importantes transformações no ambiente organizacional das empresas, afetando diretamente a formulação das suas estratégias de negócio.

A globalização das empresas transnacionais está relacionada ao desenvolvimento e expansão de redes e sistemas de informação com uma coordenação espacial de dimensões geográficas internacionais, permitindo às empresas administrar seus negócios à longa distância. Essas questões, associadas à formação dos grandes mercados regionais, isto é, Mercado Comum Europeu, Nafta e Mercosul, colocam-se como grandes desafios para as empresas na atualidade.

Em um intervalo de poucas décadas, a tecnologia de informação transformou a nossa cultura definindo os paradigmas para uma nova era organizada em torno dos grandes meios de comunicação de massa.

Por tecnologia, Castells (1996) entende o uso do conhecimento científico para especificar as formas de produzir bens de uma maneira passível de serem reproduzidos de forma sistemática. O mesmo autor define tecnologia de informação como "o conjunto de tecnologias que incluem não somente microeletrônica, computação (software e hardware), telecomunicação e ótica-eletrônica, mas também tecnologias relacionadas com a engenharia genética e suas aplicações. A engenharia genética é incluída nas tecnologias de informação, tendo em vista sua capacidade de decodificar, manipular e reprogramar códigos de informação genética.

Nos anos 90, a biologia, a eletrônica e a informática se associaram e se interligaram nas suas aplicações, nos seus materiais e mais fundamentalmente na sua abordagem conceitual. Em torno deste núcleo de informação tecnológica no sentido mais amplo, uma constelação de novos conhecimentos surgiu nas áreas de novos materiais, fontes de energia, medicina, transporte etc. Essas áreas possuem em comum uma linguagem digital na qual a informação é gerada, armazenada, recuperada, processada e transmitida. A disponibilidade de novas tecnologias de informação constitui a base para a reestruturação socioeconômica da sociedade, propiciando o surgimento de redes econômicas globais. (Network Society). (Castell, 1996)

As novas dimensões da globalização relacionam-se à emergência de um sistema mundial de interligações de redes privadas entre os principais bancos de dados e empresas industriais e de serviços nos países da "tríade" (Estados Unidos, Japão e países mais desenvolvidos da Europa). Instalamse, assim, redes mundiais corporativas que permitem à empresa interligar produção e marketing ao redor do 
globo, estimulando ampla gama de alianças estratégias, envolvendo novos tipos de interação com fornecedores, clientes e concorrentes. (Coutinho, Cassiolato e Silva, 1995).

"O verdadeiro poder da tecnologia não está em fazer antigos processos funcionarem melhor, mas em permitir que as organizações rompam com as antigas regras e criem novas formas de trabalho". (Hammer, Michael e Champy, 1994, pp. 71).

As telecomunicações, no sentido genérico da palavra, constituíram-se nos últimos anos, em excepcional fator propulsor da produtividade e competitividade, seja no âmbito interno da empresa, seja no âmbito do país. Essa potencialidade assumiu nova dimensão devido à convergência com a informática, possibilitando o aparecimento de novos serviços "teleinformáticos". A veloz incorporação dos avanços da microeletrônica viabilizou a espetacular redução dos preços relativos à capacidade de processamento e armazenamento de informações. A intensificação da concorrência entre as empresas, propiciada pelos avanços da microeletrônica, tendeu a encurtar o ciclo de vida dos produtos e a elevar os volumes em investimento em P\&D (Coutinho e Ferraz, 1994).

Esta mudança está produzindo notável convergência entre os diferentes setores do complexo eletrônico, alterando várias fronteiras setoriais. A dissolução da fronteira até então existente entre os segmentos de telecomunicações e de informática está dando lugar ao surgimento de uma nova estrutura industrial chamada de "telemática".

\section{TECNOLOGIA DE REDES DE INFORMAÇÃO}

Uma das tecnologias mais importantes adotadas pelas empresas nos últimos tempos diz respeito as EDI (Electronics Data Interchange - Redes de Telecomunicação entre Empresas), que permite a comunicação de computador a computador, aumentando a rapidez e a precisão das trocas de informação. A implantação de EDI está relacionada ao aumento do valor agregado do componente "informação" nos bens e serviços e o rápido desenvolvimento e difusão de tecnologias para processamento e distribuição dessas informações, tecnologias de informação.

A análise do ambiente das EDI é uma questão complexa e está relacionada a aspectos que ultrapassam os limites da organização e muito freqüentemente do próprio país onde está localizada a organização.

Sprague e McNurlin (1993) definem redes de telecomunicações como as rotas de tráfego de informações nos diversos meios eletrônicos. Neste sentido, elas podem ser caracterizadas como "infovias eletrônicas"(eletronic highway systems) utilizadas para promover o fluxo de informações entre indivíduos, empresas e a população em geral. Muito em breve, segundo o mesmo autor, o mundo das telecomunicações não poderá mais ser dividido em tráfego de voz, dados e imagens. Serviços, como fax, computação, videoconferência, televisão e outros, estarão disponibilizados de forma integrada.

Segundo Zilvet (1998), a tecnologia que permite essa façanha é cada vez mais viável no cotidiano dos usuários informatizados. A transmissão de informações em formatos variados só é possível mediante a difusão de tecnologias conhecida como Networked Multimidia Connection (NMC), aplicações multimídia em rede para o uso local, Intranets, e em redes transnacionais, Internet.

Do ponto de vista funcional, as redes de informação podem ser divididas em duas categorias:

- Redes de informação corporativas, de propriedade de organizações, responsáveis pelo processamento de sistemas transacionais de teleprocessamento disponibilizando serviços de acesso restrito, atuando nos diversos setores econômicos. Hoje, esse tipo de rede caracteriza-se pela veiculação de informações preferencialmente em linhas privadas de comunicação.
- Serviços de utilidade pública disponibilizados para a população em geral via Internet e outras redes abertas de comunicação. Os serviços disponíveis na área de biblioteca se enquadram nesta categoria, assim como os bancos de dados on-line, como o Dialog nos Estados Unidos.

Kamman (1990) classifica as redes de informação corporativas em três categorias:

- Redes simples (single-organization networks), cuja função é conectar uma rede de computadores pertencentes a vários departamentos de uma organização.

- Redes integradas (industry-specific value-added network) - Promovem a integração de clientes e fornecedores junto aos departamentos da empresa.

- Redes complexas (extended enterprise network) - Promovem a integração de várias empresas através do desenvolvimento de atividades cooperativas (eletronic consortium).

Podemos considerar que a tipologia anterior se enquadra em uma escala crescente de sofisticação em termos de adoção de tecnologias de teleprocessamento e computação, evoluindo das mais simples para as mais complexas.

Mariano e Dias (1996), que realizaram um estudo de caso da empresa Brahma, colocam que "a adoção da tecnologia de redes pode ser entendida como conseqüência natural do crescimento do grau de independência dos usuários, aliado às necessidades de compartilhamento de informações. A autonomia propiciada pela adoção de microcomputadores, com sua capacidade de processamentos e independência, foi possível graças às modificações de cunho gerencial que permite aos vários segmentos da empresa atuar com grau crescente de independência. Os modelos de negócio evoluíram de gestão centralizada para distribuição de responsabilidade às áreas de ponta. Portanto, a disseminação dos computadores nas empresas foi conseqüência direta tanto de modelos de gestão adotados, quanto de evoluções tecnológicas". 
Os mesmos autores também assinalam que a implantação de redes de informação permitem maior flexibilidade na empresa, propiciando crescente integração de informação entre as diversas áreas da empresa. A solução distribuída deve prover rede física, infra-estrutura de serviços (troca de informação, estrutura de compartilhamento e distribuição de dados) e softwares aplicativos (Mariano e Dias, 1996)

Com base nas colocações anteriores, realizamos uma pesquisa com três empresas do setor de telecomunicaçãoes, com o objetivo de caracterizar a estrutura e função de redes corporativas de informação. $O$ foco de atenção está voltado para a capacidade da organização em gerar e utilizar sistemas integrados de informação disseminados em redes, para subsidiar o processo de desenvolvimento/adaptação de tecnologia.

\section{MÉTODO}

\section{O universo: mercado do setor de telecomunicações}

No setor industrial de telecomunicações, a estrutura da produção mundial adquiriu características de oligopólios concentrados e estáveis. Como destaque, as quatro maiores empresas da indústria de telecomunicações - Western Electric/ATT, I.T.T.(EUA), Siemens (Alemanha) e L.M. Ericson (Suécia) - detinham, até meados da década de 80 , mais de $60 \%$ do mercado mundial e mantêm inalteradas suas posições relativas desde a década de 20.

As empresas anteriormente mencionadas, bem como as empresas Philips (Holanda), G.T.E. (EUA), G.E.C. (Inglaterra), Thomson-Brandt (França), Plessey (Inglaterra), N.E.C. (Japão), Nothern Telecom (Canadá) e C.G.E. (França), compõem o leque de empresas multinacionais que constituem uma parte do universo de pesquisa.

Segundo a International Telecomunication Union, dos US\$ 96 bilhões de faturamento proveniente das 16 maiores empresas do setor atuantes no mercado mundial, $70 \%$ dos recursos são gerados nos seguintes países:
EUA, Alemanha, Canadá, França, Suécia e Japão. Destes, as empresas européias contribuem com $59 \%$, as americanas com $28 \%$ e as japonesas com $13 \%$ (Hawkins, 1995).

No Brasil, o setor de telecomunicações está dividido em dois segmentos, a seguir apresentados:

- Centrais Telefônicas, setor predominantemente de empresas multinacionais, representado por 19 empresas com uma receita líquida de $\mathrm{R} \$ 2,8$ biIhões.

- Transmissão de dados e diversas, representado por 19 empresas de menor porte e predominantemente nacionais, com uma receita líquida de $\mathrm{R} \$ 700$ milhões.

\section{A amostra}

O presente trabalho está baseado no estudo de caso de três empresas industriais do setor de telecomunicações sediadas no Brasil, representando um faturamento de $80 \%$ do subsetor de telefonia*. Uma empresa multinacional do setor de centrais telefônicas, uma de capital misto, atuando nos dois setores anteriormente relacionados, e uma nacional atuando predominantemente no setor de transmissão de dados.

\section{A pesquisa}

Utilizou-se como instrumento de coleta de dados a entrevista semi-estruturada, isto é, foi seguido um roteiro básico para o levantamento de dados. As entrevistas foram realizadas com as chefias das área de tecnologia e desenvolvimento e suporte de software das empresas anteriormente descritas.

Realizaram-se 12 entrevistas, em um total de 24 horas de gravação.

Utilizaram-se duas formas de registro dos dados durante a entrevista: gravação direta dos depoimentos e anotações.

\footnotetext{
* Balanço Anual 95/96 - Gazeta Mercantil, p. 300 .
}

Utilizou-se um roteiro de entrevista (anexo 1), voltado para a caracterização da estratégia de negócios da empresa, com os diretores das áreas de tecnologia e chefes dos setores de informação, abordando os seguintes aspectos: dados gerais da empresa/histórico; área de atuação, participação no mercado e parcerias; estratégia de negócios atual e futura em termos de objetivos e metas; política de formação de recursos humanos e caracterização de redes e sistemas de informação corporativos.

\section{RESULTADOS}

\section{Histórico do setor de telecomunicações}

O histórico do desenvolvimento da indústria de telecomunicações no Brasil é apresentado em trabalho de Pessine (1985). Segundo o autor, a penetração das empresas estrangeiras que operam no fornecimento de equipamentos remonta ao início do século, com a criação de escritórios comerciais ou subsidiárias para importação. O processo de montagem que se seguiu foi lento e começou com as empresas Ericsson, Siemens, Standard Eletric e Philips, no período entre a Segunda Guerra e a década de 60.

$\mathrm{Na}$ década de 60 , com a perspectiva de grande crescimento da demanda, foram internalizadas as atividades propriamente industriais. Além das empresas já citadas, a NEC japonesa também instala-se no Brasil (1969). No período de 1965 e 1967, após a criação do Ministério das Comunicações e da Embratel, foram encomendadas consultorias a empresas norte-americanas, estudos sobre a estrutura da produção brasileira no setor. Estes estudos tinham o objetivo de embasar planos de expansão financiados com apoio de instituições internacionais.

À época, estimou-se que a capacidade de produção das empresas estrangeiras poderia atingir de 300 a $500 \mathrm{mil}$ linhas por ano, caso trabalhassem dois turnos. Na realidade, essas empresas não conseguiram produzir o volume previsto, obrigando o governo a realizar importações até 1974. Neste ano e nos seguintes, a capacidade produ- 
tiva das empresas estrangeiras foi marcada pela ampliação.

Foi na década de 70 que o governo criou a Telebrás, com o objetivo de planejar os serviços públicos de telecomunicações em nível nacional, seguindo diretrizes do Ministério das Comunicações: gerenciar o entrosamento das companhias de telecomunicações do governo federal; coordenar e dar assistência técnica e administrativa para as companhias de operação, indústrias e pesquisa e desenvolvimento (P\&D); obter fundos locais e internacionais para a realização dos planos e projetos aprovados pelo Ministério das Comunicações.

O mercado do setor de equipamentos de telecomunicação atingiu, em 1977, o valor de US\$1 bilhão. A partir daí, o setor foi atingido pelas limitações de investimento do setor público e particularmente pelo desvio de parcelas crescentes do Fundo Nacional de Telecomunicações (FNT) para necessidades de outros.

Uma característica marcante do comportamento do setor de telecomunicações no Brasil foi, até então, o elevado grau de interdependência entre o segmento industrial privado e os órgãos governamentais para atendimento às diretrizes referentes aos serviços prestados à comunidade. Adotouse, neste país, uma política monopolista calcada no modelo da Europa, onde a exploração dos serviços de telefonia está a cargo de organismos controlados direta ou indiretamente pelo Estado.

As atividades de desenvolvimento e exploração dos serviços de "teleinformática" se apresentavam até recentemente na forma de um monopólio natural do Estado ou privado, seja pela própria natureza destes serviços, seja pela consideração dos aspectos econômicos envolvidos na exploração de pesada infra-estrutura* .
A partir da década de 90, com a implantação da política de abertura de mercado, a competitividade está se acelerando no setor de teleinformática na busca para atingir um mercado consumidor extenso*. Nos últimos anos, com a justificativa de modernizar o setor, o governo brasileiro passou a adotar uma política calcada nos modelos dos Estados Unidos e Canadá, caracterizada por uma estrutura privada de prestação de serviços de telefonia, porém regulamentada pelo Estado.

O sistema Telebrás possuía, em operação, antes da privatização, cerca de 16 milhões de linhas telefônicas, das quais por volta de 1,9 milhão do serviço móvel celular. O objetivo do Ministério das Comunicações é chegar ao ano 2000 com uma base de telefonia móvel instalada de 9,6 milhões de acessos, e 24,7 milhões de telefonia fixa, além de colocar mais 800 mil telefones públicos (Rebouças, 1996).

A privatização da Telebrás representou para as firmas estrangeiras a conquista deste imenso mercado mediante o estabelecimento de parceria com empresas nacionais. Em conseqüência, as empresas internacionais anteriormente citadas se associaram a firmas locais para a conquista do mercado nacional e mercados regionais.

O Sistema Telebrás privatizado em julho de 98, tendo alcançado o valor de US\$ 19 bilhões, foi a segunda maior privatização em um só bloco no setor de telecomunicações no mundo. Neste processo, as grandes vencedoras foram a Telefônica de Espanha e de Portugal. "Os grupos estrangeiros compraram $32,2 \%$ do mercado de telefonia fixa e ficaram com $79,4 \%$ das linhas celulares. Eles arremataram quatro empresas e têm participação de outras seis. Investiram, sozinhos, $\mathrm{R} \$ 8,026$ bilhões, pouco mais que 0 dobro do que foi pago pelas duas telefônicas arrematadas exclusivamente por grupos nacionais $(\mathrm{R} \$ 3,874$ biIhões)". (Folha de S. Paulo, 30/7/98, cad. 1.1). As indústrias do setor de telecomunicações faturaram em 1997 por volta de $R \$ 3,5$ bilhões.

* idem 11.

\section{Caracterização das empresas}

A primeira empresa estudada, multinacional, fundada na década de 20 , possui atualmente cerca de 2.500 empregados. Começou a sua atuação produzindo e instalando equipamentos eletromecânicos atuando na área de telefonia. Há 12 anos, começou a produzir Centrais CPA* e está lançando a quarta geração desse tipo de equipamento. Atualmente, está procurando conquistar a área de telefonia móvel, apesar de a principal área de atuação ainda ser de telefonia fixa. No mercado mundial, a empresa detém por volta de $30 \%$ ** de telefonia móvel e igual porcentagem de telefonia fixa. No Brasil, ela tem uma participação de $55 \%$ do mercado da área de telefonia, dominando $40 \%$ da telefonia fixa $a^{* \star *}$.

A segunda empresa estudada, de capital misto, fundada na década de 70 , também possui aproximadamente 2.500 empregados e tem atuação bastante ampla, abrangendo as áreas de telecomunicações, informática e semicondutores. Em telecomunicações, é a líder no mercado brasileiro, onde a sua principal área de atuação ainda é a de telefonia fixa, mas com avanços na telefonia móvel como fornecedor de $70 \%$ do mercado, onde é líder no mercado nacional $^{* \star * *}$.

A terceira empresa estudada, nacional, fundada na década de 70 , possui aproximadamente 1000 funcionários. Atua na área de telefonia celular e transmissão de dados. Quanto à origem da tecnologia, possui contratos de transferência com empresas estrangeiras.

\footnotetext{
* CPA são centrais inteligentes, com capacidade para 1,5 milhões de chamadashora na base de serviços com Discagem Direta Gratuita, Caixa Postal Eletrônica e Rede Virtual Privativa.

** Financial Times 10/6/1996 - Survey p. 11.

*** Dados citados em entrevista pelo diretor da empresa.

${ }^{* * * *}$ Idem 13.
} 


\section{Análise dos dados: Estratégia de negócios}

Pudemos constar que existe uma diferença substancial entre as empresas multinacionais e nacionais do setor industrial de telecomunicações, quanto à suas estratégias na forma de condução de seus negócios. A análise dos dados mostrou que essas diferenças se manifestam principalmente em função do grau de globalização dessas empresas. $O$ fato de as multinacionais possuírem atividades econômicas distribuídas em diversas regiões do planeta, em contraposição às nacionais que concentram suas atividades em território brasileiro, influencia diretamente na forma como essas organizações se estruturaram para competir em um mercado tão dinâmico quanto o do setor de telecomunicações.

O objetivo principal das empresas estudadas é terem disponíveis soluções integradas e globais de telecomunicações para seus clientes.

Para a primeira empresa, a principal atividade é a produção de CPA's, centrais telefônicas computadorizadas. De outra parte, a companhia está, neste momento, tentando assegurar 0 mercado de telefone celular, intercâmbio de redes de dados e multimídia. A companhia tem os seguintes objetivos para os próximos anos:

1) Incrementar a participação no mercado de centros de intercâmbio de telefones computadorizados (CPA's) e no mercado de telefone celular. "O que nós vemos para o futuro é que nossa companhia, que já tem $55 \%$ do mercado de telefones fixos, aumente isto para suprir soluções completas para os clientes. Este é um serviço novo e é também conhecido como turn key."

2) Melhorar a performance dos seus produtos, principalmente o desenvolvimento de software. Atualmente, a produção de equipamento de intercâmbio de telefone digital representa $30 \%$ em hardware e $70 \%$ em software. "Nós trabalhamos no desenvolvimento do software de tarifas em cooperação com a Holanda e a Suécia". Este software é utilizado mundialmente pelos equipamentos da empresa.
A segunda empresa tem por objetivo a diversificação dos produtos em ambos os mercados; nas áreas de comutação de voz e comunicação de dados com inovação tecnológica baseada na empresa matriz. Para manter a liderança do mercado de telefonia celular, um dos entrevistados afirmou que o Brasil oferece um dos maiores mercados em telefones celulares e a empresa é muito competitiva nesta tecnologia. Com o objetivo de assegurar o mercado, a empresa está investindo no desenvolvimento de nova tecnologia, que significa redes multimídia de alta velocidade. Depois da privatização, o principal objetivo da empresa para os próximos anos é assegurar o mercado privado, no qual tem pouca representação até o momento. "A equipe de desenvolvimento analisa o mercado, em termos de demanda de novas tecnologias e serviços e tenta convencer a alta administração da matriz quanto às oportunidades relacionadas com a introdução desses novos produtos e serviços. Esse é um processo complicado porque, às vezes, a empresa brasileira solicita essas novas tecnologias, e a sede não está interessada em oferecê-las. Quando a decisão é tomada, a transferência de novas tecnologias entre as duas empresas tem de ser negociada".

A terceira empresa tem como objetivo consolidar a área de transmissão de dados competindo em preço e qualidade com as empresas estrangeiras. Pretende estabeler contratos de transferência de tecnologia com empresas estrangeiras de origem européia, consolidando desta forma sua posição no mercado.

A seguir, analisaremos mais dois aspectos que julgamos estratégicos para a condução dos negócios na empresa: a capacitação dos recursos humanos envolvidos em atividades de pesquisa e o desenvolvimento e gerenciamento dos recursos informacionais, em especial quanto ao uso de redes corporativas de informação como apoio ao desenvolvimento tecnológico na empresa.
Política de treinamento de recursos em pesquisa e desenvolvimento

Do ponto de vista qualitativo, as empresas multinacionais possuem um programa de capacitação mais extenso (em média 160 horas anuais) e mais diversificado (com treinamentos no país e no exterior) que as empresas nacionais. Esses treinamentos que são registrados no início e no decorrer da carreira técnica, de forma contínua, estabelecem um distanciamento entre os funcionários das empresas estrangeiras e nacionais.

A primeira empresa tem seu centro de treinamento técnico no Brasil, que é um dos 40 centros desse tipo apoiado pela matriz. O pessoal é treinado para melhorar suas habilidades técnicas e gerenciais. A companhia também oferece treinamento para gerentes brasileiros no centro de treinamento da matriz na Europa, que contrata professores universitários de todas as partes do mundo para treinar a equipe gerencial e a diretoria por um período de dois meses por ano.

A segunda empresa tem forte política de treinamento e oferece treinamento não só para seus empregados, mas também para seus clientes. A empresa tem um edifício em São Paulo dedicado ao treinamento de pessoas, e todos aqueles que se integram à companhia fazem, inicialmente, seis meses de treinamento. Com o objetivo de administrar esses cursos, consultores são contratados do setor privado, isto é, de outras companhias e universidades. Professores estrangeiros oriundos das empresas do grupo no exterior também ministram treinamento especial no Brasil. A empresa também oferece treinamento no exterior para seus executivos. "No momento, a empresa tem um novo projeto em que 12 pessoas estarão sendo treinadas na matriz, nos próximos dois anos. Quando esse grupo retornar ao Brasil haverá um programa de integração no sentido de disseminar (através de cursos e seminários) seus ganhos recentes de conhecimento". A companhia tem também um grupo de doze pessoas gate-keepers que participam nos principais eventos pelo mundo, discutindo novas tecnologias e pesquisa. Esse grupo viaja para o 
exterior por um mês inteiro, pelo menos duas vezes ao ano, com todas as despesas pagas pela companhia.

A terceira empresa, nacional, possui um vínculo com uma Faculdade de Engenharia fundada pelo próprio dono da empresa. Praticamente todos os engenheiros da empresa começam como estagiários, ainda estudantes, sendo contratados depois de formados. Desta forma, a empresa possui um manancial de recrutamento de técnicos pelos quais a própria organização é responsável pela manutenção. Existe uma ligação intensa em termos de atividades acadêmicas e de pesquisa. A empresa é utilizada pela Faculdade como laboratório experimental, e os diretores e técnicos também são professores da escola. A diretoria é a mesma em ambas as organizações. Entretanto, quando a empresa introduz uma nova tecnologia, utilizase de um convênio com uma empresa italiana que oferece treinamento para os técnicos brasileiros. Esta modalidade de treinamento tem ocorrido nos últimos cinco anos, mas não foi possível quantificar o número de pessoas treinadas no exterior.

Concluindo este tópico, entendemos que nas empresas do parque industrial de telecomunicações, por se tratarem de empresas possuidoras de tecnologias de ponta, a questão da produção e do conhecimento corporativo são condições essenciais para a sobrevivência em um mercado tão turbulento. Em conseqüência, a defasagem quanto à política e capacitação de recursos humanos entre as empresas multinacionais e nacionais certamente poderá inviabilizar a sobrevivência das empresas nacionais.

Quanto à procura de capacitação de treinamento em instituições externas, por meio cursos de pós-graduação em nível de especialização, mestrado e doutorado, observamos que, em geral, não existe diferenças substanciais entre as empresas multinacionais e nacionais. Essa forma de treinamento é pouco valorizada pela direção das organizações em ambas as modalidades de empresa, relacionando-se mais a iniciativas individuais do que a uma política institucional. Entretanto, pudemos perceber que, nas empresas na- cionais onde os programas de treinamento são menos freqüentes, os técnicos, sentindo os efeitos da concorrência no mercado de trabalho, recorrem com mais freqüência a essa forma de treinamento junto às estruturas formais de instrução. Neste sentido, podemos supor que os técnicos das empresas nacionais são mais sensíveis a esse tipo de treinamento do que os técnicos das multinacionais, mais engajados com a cultura organizacional da empresa. Podemos supor que esses elementos em treinamento nas universidades acabam se desligando da empresa, realocando-se nas empresas multinacionais sediadas no Brasil e no exterior. No passado, esse movimento ocorria de forma inversa, isto é, técnicos oriundos de Institutos de Pesquisa Estatais, após se capacitarem, deslocavam-se para a iniciativa privada, em busca de melhores salários (Pontes, 1994). Hoje, o deslocamento ocorre dentro do próprio ambiente empresarial. Essas constatações vêm ao encontro das análises de Druker (1993), que define a organização como um grupo de especialistas que trabalham em conjunto em uma tarefa comum. Esses especialistas em conjunto formam a "base de conhecimento especializado". É essa "base de conhecimento especializado" que dá significado à organização e ao nível de competitividade da empresa em relação ao meio externo.

\section{Uso de Redes Corporativas de In- formação}

O último aspecto analisado neste trabalho relaciona-se ao acesso a uma base de conhecimento corporativa disseminada pela rede de informação das empresas. O uso de redes de informação pelas empresas pode ser representado por quatro níveis: automação de funções administrativas; automação do setor de produção; automação das funções de marketing e criação de uma rede corporativa privada onde clientes e fornecedores podem acessá-la.

Podemos considerar que as companhias multinacionais analisadas se encontram no quarto nível. As redes internacionais identificadas nessas companhias são utilizadas tanto pela alta administração quanto pelo departamento de desenvolvimento.

O gerente do setor de computação da primeira empresa afirmou: "Atualmente cada analista de sistema está conectado on-line, 24 horas por dia, com a empresa matriz (na Suécia) e com todos os setores no Brasil, por meio de uma rede de estações de trabalho que, transmitindo informações na velocidade de 512 kilobites por segundo, permite a instalação e a transmissão da tecnologia de videoconferência. A rede permite acesso e comunicação on-line às livrarias eletrônicas da companhia no mundo inteiro e é responsável pela disseminação das tecnologias desenvolvidas na empresa".

Com relação à segunda empresa, em termos de rede internacional, o departamento de desenvolvimento tem uma rede de estações (Sun) de trabalho utilizando o software UNIX ligado diretamente à empresa matriz, trabaIhando on-line, 24 horas por dia". Neste caso, o acesso ao banco de dados da empresa da sede encontra-se protegido por um sistema de segurança em que os usuários são classificados em termos da sua posição hierárquica na empresa. Esse processo de sigilo à informação ocorre entre a empresa matriz no exterior e a subsidiária no Brasil.

Finalmente, a terceira empresa possui uma rede interna com três servidores e 300 computadores. A empresa também possui uma rede externa como provedora de serviços à Internet. Esta rede está sediada na Faculdade de Engenharia do grupo e oferece serviços tanto para usuários internos quanto externos. Por meio dessa rede, todas as empresas do grupo estão interligadas.

Concluindo a análise deste aspecto, podemos observar, pelos depoimentos, que as empresas multinacionais analisadas estão conectadas 24 horas a um computador central localizado na empresa matriz. Isto permite que todas as tecnologias produzidas no Brasil possam ser transferidas para as empresas sedes . 


\section{CONSIDERAÇÕES FINAIS}

Levando em consideração as questões anteriormente abordadas, podemos inferir que empresas industriais multinacionais do setor de telecomunicações sediadas no Brasil estão implantando e mantendo redes corporativas de informação conectadas às matrizes e transferindo os estoques de conhecimento e tecnologias produzidas nos países periféricos. O movimento inverso, isto é, a transferência de informação dos países centrais para os periféricos não ocorre com a mesma freqüência. Em uma das entrevistas, foi dito que $50 \%$ das tecnologias utilizadas nesse setor mudam a cada dois anos e que em cinco anos todas as tecnologias se tornam obsoletas. Essas são produzidas principalmente pelas companhias mães, e as companhias subsidiárias apenas adaptam-nas para fazê-las funcionar no mercado brasileiro. O problema é que isto coloca as companhias subsidiárias dependentes das matrizes. As transferências de novas tecnologias da subsidiária e a melhoria ou produção de novos bens dependem da decisão política das matrizes.

Podemos supor que a possível falta de competência das empresas nacionais para reelaborar as informações recebidas do exterior e realimentar os estoques com informações novas, disponibilizando-as em redes corporativas, poderia estar inviabilizando o desenvolvimento do setor na indústrial nacional.

Por outro lado, constatamos que, na década de 70 , foi implantada uma política de ciência e tecnologia influenciada por uma ideologia nacionalista, tendo, como um dos objetivos, induzir, para o país, a geração de tecnologias consideradas estratégicas, em termos de segurança nacional. A pesquisa tecnológica no setor industrial militar foi priorizada. O setor de telecomunicações foi incluído tanto pela sua importância em termos da sua posição estratégica nas comunicações, quanto pelo controle dos aeroportos e espaços aéreos.
Entretanto, de acordo com essa política, esses setores eram controlados pelo Ministério das Comunicações, com o objetivo de encorajar o desenvolvimento de instituições de pesquisa tecnológica em parceria com indústrias do setor de telecomunicações.

Uma das medidas foi determinar que as empresas do setor tivessem mais de $51 \%$ de ações de propriedade de pessoas físicas ou jurídicas brasileiras. Empresas multinacionais que operavam no Brasil, algumas desde o início do século, foram obrigadas a se associar a grupos econômicos nacionais, como é o caso de duas empresas citadas neste trabalho.

Outras conseqüências dessas políticas foram os incentivos focalizados, em larga medida, nos projetos de pesquisa de alta tecnologia envolvendo investimentos pesados e inúmeros grupos de pesquisadores.

Um exemplo disto foi a pesquisa espacial da construção de satélites envolvendo instituições de pesquisas e industriais relacionadas com o CTA Centro Tecnológico Aero-Espacial em São José dos Campos.

Outros exemplos similares podem ser observados em outras áreas de pesquisa tecnológica, como desenvolvimento de software, hardware, construção de radar, fibras óticas etc. As instituições envolvidas neste projeto receberam amplo recurso financeiro oriundos do orçamento das forças armadas. A intenção dessa medida era colocar o Brasil no mesmo padrão dos países do primeiro mundo em termos de desenvolvimento tecnológico. Nesse período, foi criada a Telebrás, com o objetivo de organizar os serviços de telecomunicações brasileiras e coordenar a relação entre as indústrias de equipamentos, companhias operadoras e institutos de pesquisa.

$\mathrm{Na}$ segunda metade dos anos 80 , o panorama político brasileiro sofreu importantes transformações, principalmente no que tange ao papel do governo militar.
$\mathrm{Na}$ área de ciência e tecnologia, o foco sobre a indústria armamentista como prioridade central foi substituída pela ênfase em pesquisas orientadas para o desenvolvimento social e econômico, tais como biotecnologia, química fina, conservação ambiental e novos materiais.

Nos anos 90, com a implantação de uma política econômica baseada em um modelo neoliberal, as restrições ao investimento estrangeiro em alguns setores, como a indústria de telecomunicações e computação, foram liberadas. Conseqüentemente, as empresas brasileiras que nos últimos 25 anos tinham se expandido devido a uma política protecionista foram obrigadas a competir com empresas multinacionais, colocando-se em desvantagem com relação a estas.

Por outro lado, a infra-estrutura de pesquisa em universidades e outras instituições que durante os anos 70/ 80 tinham recebido generosos fundos foram negligenciadas, resultando no declínio de importantes centros de pequisa.

Desse modo, estamos nos deparando com o desmonte desses importantes centros de pesquisa, ocasionando a transferência do conhecimento acumulado para o setor privado e conseqüentemente o fechamento do acesso público a esse conhecimento, assim como estamos observando a perda da competitividade da empresa nacional do setor de teleinformática, implantada na década de 70 sob os auspícios de uma política econômica protecionista do Estado.

A partir das colocações anteriores, encaminhamos as seguintes questões:

Quais são as perspectivas da indústria brasileira do setor de telecomunicações em um mundo em mudanças? O futuro que se desenha para ela pode trazer desafios importantes. As empresas nacionais necessitam melhorar a qualidade de seus produtos e diminuir custos, para competir com as empresas multinacionais modernas que, no cenário mundial, encontram-se em estágios mais avançados de desenvolvimento tecnológico. 
Por outro lado, hoje, com a explosão das redes de informações internacionais, com o advento das novas tecnologias de informática e telecomunicações, a atividade de recuperação de informação passa a exigir competência e uso de técnicas modernas, propiciando o aparecimento de redes transnacionais de informação, de propriedade de corporações, que as utilizam como poderosíssimo instrumento gerencial para impulsionar a inovação tecnológica e o processo de tomada de decisão. Esses desafios colocam as empresas nacionais em uma situação extremamente crítica, em desvantagem com relação à empresa multinacional, cujos reflexos na política estamos presenciando na imprensa, dia-a-dia, com as discussões em torno da política de privatização do setor.

\section{Strategic information management within industrial enterprises of telecommunications sector in Brazil}

\author{
Abstract \\ A comparative study within three industries \\ of telecommunications sector, with \\ headquarters in Brazil, has been carried out, \\ laying emphasys on assistance to the \\ organization staff training in regard to \\ information system management in order to \\ subsidize the process of development/ \\ adaptation of new technologies. The main \\ topics dealt with are business strategy \\ feature, policy for human resources training \\ in research and development, and use of \\ corporate information networks for the \\ development of new technologies.
}

\section{Key words}

Business information; Corporate information networks; Information transfer in research and development.

\section{REFERÊNCIAS BIBLIOGRÁFICAS}

1. BARRETO, A. A questão da informação. São Paulo, Perspectiva, 8(4) 1994 pag 3a 8

2. BELL, D. O advento da sociedade pós-industrial, São Paulo, Cultrix, 1974.

3. BURK, C \& HORTON, F. Infomap - A complete guide to discovering corporate information resources. Prentice Hall, 1988

4. CASTELLS, M. The information age: economy. society and culture. vol. I. The Rise of the Network Society. Oxford, Blackwell, 1998.

5. COUTINHO, L. \& FERRAZ, J. C. Estudo da Competitividade da indústria brasileira Campinas, Papirus, 1994.

6. COUTINHO, L.; CASSIOLATO, J. \& SILVA, A. N. Telecomunicações, Globalização e Competitividade . Campinas, Papirus, 1995

7. DOWBOR, L. Sociedade do conhecimento. São Paulo, Pioneira, 1994.

8. DRUCKER, P. Sociedade pós-capitalista. São Paulo, Pioneira, 1993

9. GAZETA MERCANTIL - Balanço Anual 95/96.

10. HAWKINS, Infra-Estrutura de Informação e Comunicações: Ambições Globais e Realidades Regionais. In: COUTINHO, L.; CASSIOLATO, J. \& SILVA, A. N. Telecomunicações, Globalização e Competitividade, Campinas, Papirus, 1995
11. HOBDAY, M. Telecommunication in developing countries: the challenge from Brazil. Londres, Routledge, 1990.

12. KAMMAN, A. Global Networks, stage by stage. Lexington, Nolan, Norton \&Co, 1990.

13. MARIANO, S.R.H.; DIAS, D.S. Downsing em tecnologia: o caso da Brahma. São Paulo, Revista de Administração - USP, v.31 n.4 out/dez, 1996.

14. NAISBITT, J. Paradoxo Global. Rio de Janeiro, Campus, 1994.

15. PESSINI, J. E., A indústria brasileira de telecomunicações - diagnóstico setorial, Relatório do Conselho Unicamp/I.E./ SICCT, março 1985.

16. PONTES, C. C. Institutos de pesquisa tecnológica e serviços de informação. Brasília, Ciência da Informação, v.23, maio/ ago 1994.

17. SPRAGUE JR.; R.H. MCNURLIN, B.C. Information systems management in pratice. Prentice-Hall, 1993.

18. UEHARA, J. M. Cenários de Telecomunicações, Campinas, CPqD/Telebrás, 93.

19. ZILVETI, M. Multimídia agora é gerada em rede. Folha de $S$. Paulo, 28 de janeiro de 98 , cad $5 / 3$.

\section{Cecília Carmen Cunha Pontes}

Professora titular da Faculdade de Biblioteconomia e Instituto de Informática. Pontifícia Universidade Católica de Campinas (PUC-Campinas)

cpontes@acad.puccamp.br 